가톨릭대학교 의류학과

\title{
A Study of the Development of Women's upper Clothing based on a Traditional Korean Style using the Decorative Techniques of the Jatmulim
}

\author{
Eun-Jung Kim ${ }^{\dagger}$ \\ Dept. of Clothing \& Textile, The Catholic University; Seoul, Korea
}

\begin{abstract}
This study suggests a new women's upper clothing based on traditional Korean costumes that utilize the Jatmulim. The Jatmulim is an example of the skill found in conditional Korean costumes and is of a small triangular shape. Jatmulim was developed in size, shape, and arrangement through the method of making and using children's Durumagi, the dancer's or shaman's Mongduri, and modern works. A total of five pieces of different women's clothing were suggested by applying the developed Jatmulim. In the first piece, the clothing is a woman's sleeveless blouse based on the construction of the Yoseon-Cheolik from the Joseon period and made with a larger sized Jatmulim in the back of the neckline and shoulders. In the second piece, the clothing is designed for a woman's jacket based on the Bansuui of the Joseon period with rectangular Jatmulim in the front neckline and at the end of the sleeves. In the third piece, the clothing is designed for a woman's sleeveless blouse based on the Danryeong with rectangular Jatmulim in the neckline. In the fourth piece, the construction of the Jeogori is applied to the clothing for making a woman's jacket that has a bigger sized Jatmulim in the front part as a decoration. In the fifth work, the clothing is designed for a sleeveless blouse based on the Dapho with a different sized arrangement of the Jatmulim in the neckline.
\end{abstract}

Key words: decorative techniques(장식 기 법), development of women's upper clothing(여성상의 개 발), Jatmulim(잣 물 림), Korean traditional decoration(한국전통장식)

\section{1. 서 론}

한복은 한국문화를 대표하는 전통복식으로 확고한 자리를 유 지하고는 있으나 결혼, 돌잔치, 명절 등 특정한 행사에만 활용되 고 있어 그 아름다움을 지속적으로 알리고 홍보하기에는 한계가 있다. 이에 90 년대 이후 전통한복 고유의 아름다운 선을 그대로 살리면서 기능상의 불편함을 해소한 생활한복이 활성화되고(Choi, 1999), 한국적 소재인 모시를 이용한 상의를 개발하는(Yu, 2012) 등 한복의 생활화를 위한 노력이 끊임없이 이루어지고 있다. 하 지만 생활한복은 서양복이 일상복으로 된 현실에서 대중적으로 입혀지기에는 여전히 형태, 소재 등의 문제점과 함께 서양복과 의 어울림에 있어 한계가 있다. 따라서 한복의 아름다움을 일상 화시키기 위한 노력의 하나로 한복의 미가 반영되고 서양복과도 잘 어울릴 수 있는 아이템 개발이 필요하다.

한복은 선, 색, 문양, 소재, 장신구 등으로 그 아름다움이 표 현되고(Gum, 1994) 세부적으로는 장식기법에 의해 한국적 미

†Corresponding author; Eun-Jung Kim

Tel. +82-10-8378-4124

E-mail: emilymaum@gmail.com
를 표현할 수 있다. 특히 한복의 장식기법은 저고리의 깃, 고 름, 끝동과 치마폭에 활용되어 변화를 주는데, 이는 형태 변화 가 다양하지 않은 전통복식에서 형태의 큰 변화 없이 새로운 디자인으로 제안할 수 있는 효과적인 방법이다.

한복의 장식기법은 $\mathrm{Kim}$ and Lee(2010)의 연구와 Ok and $\operatorname{Park}(2011)$ 의 연구에서 보면 ‘금, 은박, 자수, 색동, 조각 잇기, 아플리케, 선치기, 스티칭, 누비, 그림 그리기, 잣물림, 매듭, 핀 턱, 수모, 염색, 혼합기법 등이 있다. 이러한 장식기법은 새로 운 디자인을 개발하는데 이용되었는데, $\operatorname{Kim}(2003)$ 은 누비를 활 용하여 패션에 응용한 디자인을 제시하였고, Lee(2011)는 조각 보의 조형성을 응용하여 복식 디자인에 응용하였으며, Lee and Choi $(2007,2009)$ 는 한국 전통자수를 현대 패션디자인에 응용 하였다. 이처럼 몇몇의 한국 전통장식 기법은 꾸준히 활용되는 반면 잣물림과 같은 부수적인 기법은 디자인 개발에서 활용되 지 못하였다. 따라서 본 연구에서는 한국 전통 장식기법을 활 용한 상의 개발연구를 함에 있어 그동안 주요 장식기법으로 활 용되지 않은 잣물림 기법을 응용해 보고자 한다. 잣물림 기법 이 깃선, 치마폭, 끝동선, 소매, 고름, 섶선 등에 활용되고, 특 히 치마폭을 제외하고는 저고리 장식기법으로 자주 활용된 점 (Kim \& Lee, 2010)과 제작이 간편하고 현재까지 다양한 변화 
를 시도하지 않았던 점에 주목하여 잣물림 기법을 현대적인 여 성복의 치마나 바지와도 잘 어울릴 수 있는 한국적 여성상의 디자인에 접목해 보고자 한다.

연구의 방법과 내용은 잣물림 제작 방법에 관한 이론적 고 찰과 유물, 작품을 통한 실증 고찰을 함께 병행하여 잣물림을 응용한 기법을 개발하고 이를 조선시대 출토유물 중 상의 디자 인에 도움이 되는 실증적 자료를 토대로 한국적 여성상의 다자 인에 응용하여 제작하고자 한다.

본 연구는 한국 전통 장식기법을 알리고 이를 응용하여 한 국적 복식 디자인에도 활용할 수 있는 장식기법을 개발하고 보 급하는데 그 의의가 있다.

\section{2. 잣물림의 이론 및 실증 고찰}

\section{1. 잣물림의 정의}

잣물림은 장식 봉제의 하나로 상침질, 사뜨기, 쌍미리 달기, 누비박기, 색동 등과 함께 쓰인 한국 전통 장식기법으로, 이러 한 장식기법에 관한 역사적 문헌 기록은 확인할 수 없었다. 따 라서 잣물림 장식기법은 유물을 통해 혹은 제작자들의 기술 전 승에 의해 확인할 수 있다. 잣물림은 여러 색의 조각 천을 세모 지게 접어 만든 후 솔기에 색색이 끼워 물리는 장식방법이다. 주 로 어린아이 옷의 깃이나 겉섶 솔, 조각보, 주머니 등에 사용하 였고, 한복을 만들고 남은 천들을 모아두었다가 필요할 때 이 용하였다(Hong et al., 2004).

Table 1은 잣물림의 제작과정으로, 여러 가지 색의 얇은 감 을 $1 \mathrm{~cm}$ 정도의 정사각형으로 자른 후 반으로 3 번 접어 삼각형 을 만든 다음 시접이 보이지 않는 쪽이 $0.3 \mathrm{~cm}$ 밖으로 가도록 자리를 맞춰가며 꿰맨다. 저고리의 깃 둘레나 진동둘레뿐만 아 니라 타래버선, 조각보 등 여러 곳을 색색의 잣 모양을 만들어 장식하는데, 귀엽고 아기자기한 이미지를 주어 주로 어린이 한 복에 많이 쓰이며, 현대에는 은은한 색으로 배색하여 여자 한 복의 깃과 치마폭에(Lee, 2011) 포인트로 쓰이고 있다.

\section{2. 잣물림 장식의 유물}

잣물림이 장식된 유물에는 19 세기 말, 20 세기 초 어린이의 색동두루마기와 몽두의(몽두리)가 있다.
Table 2. Chidren's Durumagi in the Joseon Period

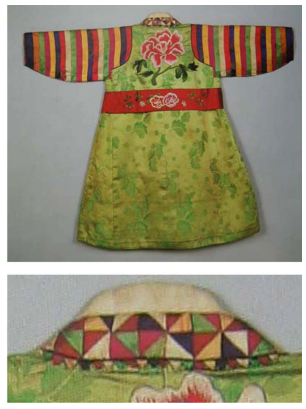

Girl's Durumagi. Korean Embroidery (2000), p.59.

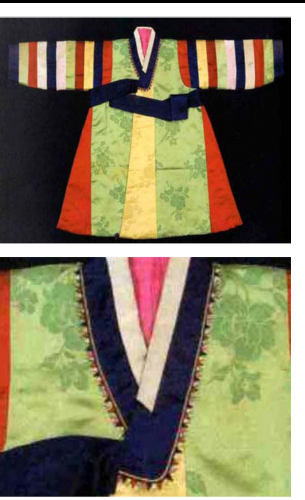

Boy's Durumagi. A Comprehensive Catalogue of Korean Costume from The National Folk Museum of Korea Collection (2005), p.190.
Table 2는 19세기 말, 20세기 초 어린이 두루마기에 장식된 잣물림 장식이다. 왼쪽의 사진은 여아의 색동두루마기인데 깃 선에 $5 \mathrm{~mm}$ 내외 흰색, 초록색, 빨강색, 노란색, 파랑색, 분홍색 의 잣물림이 반복되면서 장식되어 있다. 이러한 다채로운 잣물 림의 색상은 깃에 보이는 삼각형 조각장식과도 동일한데, 이는 소매의 색동 조각 천을 활용하여 장식한 것으로 보인다. Table 2 의 오른쪽 사진은 20 세기 남아의 두루마기로 왼쪽의 여아 두 루마기와 같이 깃 선에 $1 \mathrm{~cm}$ 내외 잣이 장식되어 있으며 색상 은 소매에 사용된 색동 색과 동일한 것으로 남색, 연두색, 빨 간색, 흰색, 분홍색, 노란색이 사용되었고, 이 또한 소매의 색 동 조각 천을 이용하여 장식한 것으로 보인다. 이상 어린이의 색동두루마기에서 확인되는 잣물림은 크기가 $1 \mathrm{~cm}$ 내외이며 소 매에 사용된 색동천을 활용하여 깃 선에 장식한 것을 확인할 수 있었다.

잣물림이 장식된 또 다른 종류의 유물에는 Table 3의 몽두의 가 있다. Cultural Heritage Administration(1981)에 의하면 몽 두의는 조선시대 궁중에서 정재(呈才)를 출 때 여기(女妓)나 무 당이 입던 무의로 형태는 두루마기와 비슷한 표의이며 궁중무 희가 입었다는 설과 무당의 옷 등 아직 그 착용자에 관해서는

Table 1. How to make Jatmulim

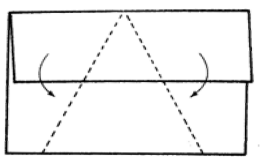

First, prepare the colored cloth for making it triangle shape.

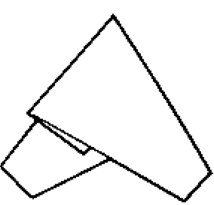

Second, make Jat.

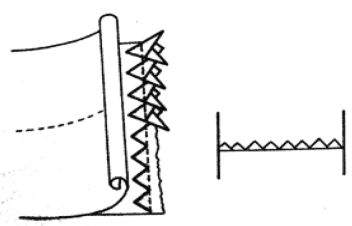

Third, put Jat between the cloth. 
Table 3. Mongduri

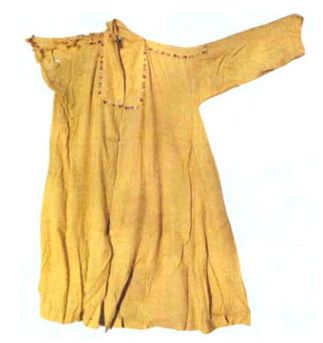

Court Dress in the Joseon Period (1981), p.102.

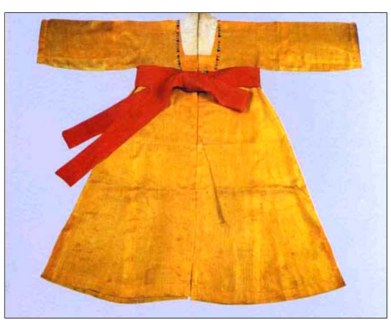

Costume (2006), p.121.
명확하지 않다. 특히 Table 3의 왼쪽 몽두의는 창덕궁에 소장 된 것으로 황색 명주로 된 홑옷이며 그 형태는 두루마기와 같 이 트임이 없으나 겉섶과 안섶이 같은 치수로 달려 있어 좌우 가 동일하고 옷고름이 없다는 면에서 두루마기의 구성과 차이 가 있다. 이 유물에는 옷깃 주위와 어깨에 잣이 색색으로 장식 되어 있는데, 잣의 크기는 $1 \mathrm{~cm}$ 인 정삼각형이며, 분홍색, 자주 색, 미색, 황색, 주황색, 북청색의 순서이다. 오른쪽의 몽두의는 20세기 초의 몽두의로 왼쪽의 것과 비교하면 형태면에서는 동 일하나 고름이 달려 있고 깃 선에만 잣물림 장식이 되어 있는 점에서 차이가 있다. 이상의 몽두의 유물에서 확인된 잣물림 장 식은 깃선 혹은 어깨선에 어린이의 두루마기에서 확인되는 다 채로운 색상으로 장식되어 있음을 알 수 있었다.

\section{3. 잣물림 장식의 현대디자인}

잣물림은 전통 한복 외에도 Table 4 와 같이 생활한복, 장신 구, 소품에 활용되었다. 잣물림은 Lee(2011)의 연구에서 보면 2000년대부터 2009년대까지의 한복의 장식기법에서 단독으로 장식되기보다는 두 가지 이상의 장식기법과 혼합되어 깃선 치 마폭선 등에 장식되어 나타났다. 1999 KOSCO Exhibition
(1999)의 '온고지신(A lesson from the past)'은 산뚱 실크와 노방을 이용하여 생활한복을 제작하였는데 치마 아래 부분에 삼각형 모양으로 잣물림 장식을 하였고, 저고리의 섶선, 깃선, 소매의 끝동선에 빨간색과 흰색으로 잣물림 장식을 하였다. $2000 \mathrm{KOSCO}$ Exhibition(2000)의 ‘품격'의 작품은 진주사와 노방을 이용하여 조끼허리가 달린 한복 치마의 형태를 이용한 원피스로서, 목선과 진동선에 전통장식 기법인 잣물림 기법을 포인트로 사용하였다. Table 4 의 여아의 배씨 댕기를 응용한 머 리띠는 가장자리를 잣물림으로 장식하여 화려하고 귀여운 여아 의 한국적 머리띠로 제작한 것이다. International Costume Conference(2003)의 감물로 염색된 가방 작품은 삼각형 모양을 연결하여 가방의 앞부분에 장식하였는데, 이는 잣물림의 형상 을 응용한 것으로 보인다.

이상 현대 복식에 활용된 잣물림은 생활한복의 치마 내부 선 및 상의의 깃 또는 목선, 소매 등에 장식되었고, 머리띠 및 가 방에 장식기법으로 활용되었으나 주로 기본 원형에 벗어나지 않게 장식되어져 이를 응용한 장식기법의 개발과 다양한 복식 에의 활용이 필요하였다.

\section{3. 잣물림을 응용한 한국적 상의 디자인 개발}

본 장에서는 잣물림의 기본 방법에서 크기, 형태, 배열을 변 화하여 새로운 잣물림 기법을 개발하고 이를 한국적 여성상의 디자인 개발에 활용해 보고자 한다.

\section{1. 잣물림 응용기법}

잣물림의 응용기법은 Table 5 의 크기의 변화, 형태의 변화, 배열의 변화로 응용할 수 있다.

크기의 변화는 잣물림 모양의 크기를 기존의 $0.5 \mathrm{~cm}-1 \mathrm{~cm}$ 내 외의 작은 크기에서 $2 \mathrm{~cm}$ 이상 확대하여 응용하는 것으로 의 복의 화려함을 부각시킬 수 있을 것이다. 또한 크기의 변화에

Table 4. Costumes with Jatmulim

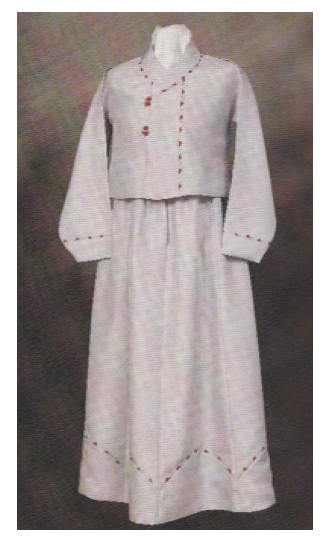

1999 KOSCO Exhibition (1999), p.77.

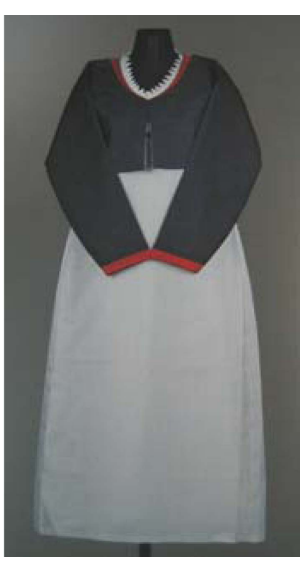

2000 KOSCO Exhibition (2000), p.40
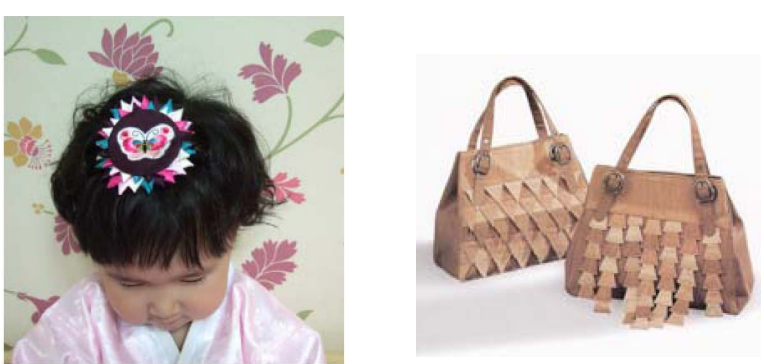

Hairband. http://blog.naver.com/fviam
International Costume Conference (2003), p.80. 
Table 5. Changed Jatmulim

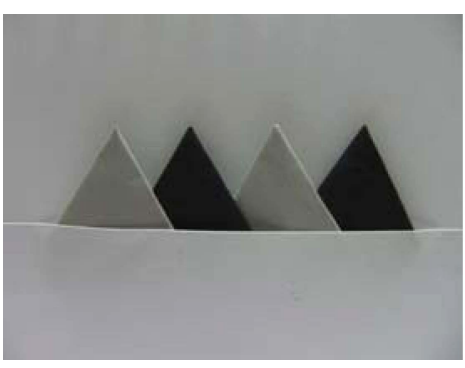

Changed size
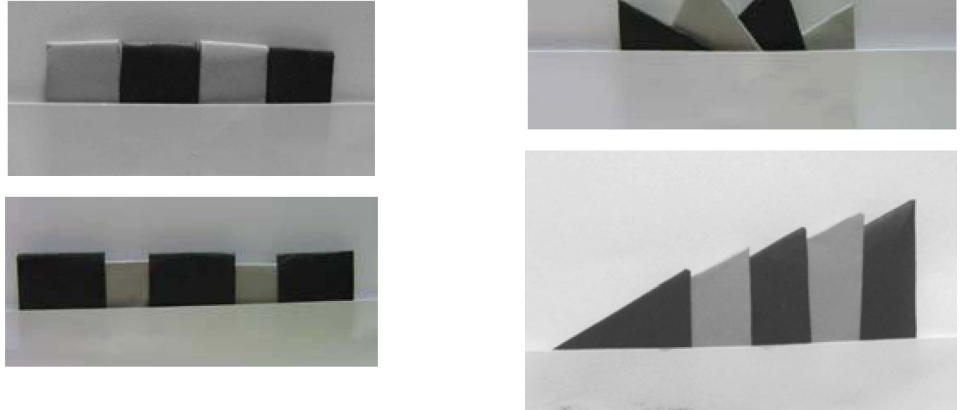

Changed arrangement
는 불규칙한 크기의 잣물림을 장식하여 단조로운 반복에서 리 듬 있는 반복으로 변화를 줄 수 있다.

형태의 변화는 잣물림의 제작 기법을 응용한 것으로 천 조 각을 접어서 모양을 만들되 삼각형 모양뿐만 아니라 사각형 모 양으로 만들어 활용하는 것으로 다양한 이미지를 만들어 의복 의 한 부분이 될 수 있도록 한다.

배열의 변화는 잣물림의 크기와 형태의 변화와 함께 잣물림 의 배열 방법과 장식되는 위치를 변화시키는 것이다. 즉 일반 적으로 잣물림은 직선으로 장식되어 있는데, 이를 부채꼴 형태 로 넓혀 장식하거나 크기에 차이를 두어 겹쳐 장식을 함으로써 변화된 모습을 보여 줄 수 있다. 이와 함께 잣물림 기법은 장 식되는 위치를 연결 선 사이에만 두어 장식하는 것이 아니라 깃, 소매, 소매 단, 섶 등 의복의 한 부분 혹은 의복의 끝선에 장식하여 응용할 수 있다.

\section{2. 잣물림을 응용한 한국적 상의 디자인}

앞서 제시한 잣물림의 응용방법과 조선시대 유물을 바탕으 로 하여 한국적 상의 다섯 작품을 제시하였다.

Design 1은 Fig. 1의 조선시대 요선철릭을 응용하여 제작한 한국적 여성 상의로 민소매 블라우스이다. 요선 철릭은 고려시 대부터 조선시대 전기의 유물에서 확인되는 남자 포의 하나로 상의와 하의가 연결되어 있고 특히 허리선에 선장식이 되어 있 는 점이 특징이며(Yu \& Kim, 1998), 허리아래의 부분은 치마 처럼 풍성한 실루엣을 보인다. 이러한 형태적 특성을 응용하여 Table 6의 페플럼(peplum)이 있는 민소매 상의(sleeveless blouse) 로 제작하였는데, 목둘레와 어깨 끝에 잣물림의 크기를 크게 하 여 장식함으로써 귀엽고 여성스러운 느낌을 부각하였다. 특히 잣 물림은 Fig. 2에 제시된 크기의 변형으로 목둘레 부분은 약 $4 \mathrm{~cm}$, 양쪽 어깨에 있는 잣물림은 $3 \mathrm{~cm}$ 정도의 크기로 제작하 여 장식하였고 연결선이 아닌 외각 선에 장식함으로서 배열의 변화를 준 잣물림 기법을 활용하였다.

Design 2는 Fig. 3의 조선시대 반수의를 응용하여 제작한 한 국적 여성 상의로서 재킷(Jacket)으로 제작하였다. 반수의는 U

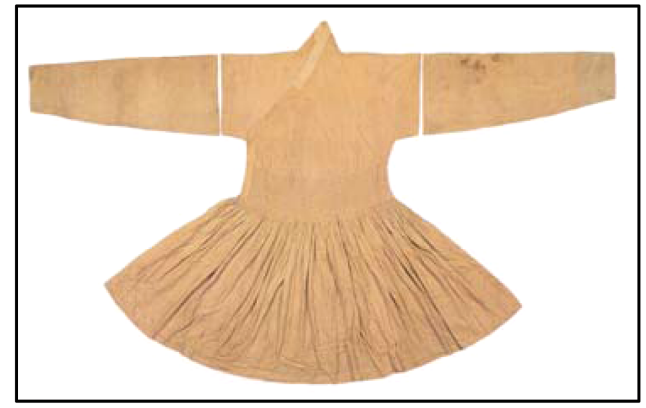

Fig. 1. Yoseon-Cheollik. Silence of 500 years and Reincarnation; Donation Exhibition of Wonju Byeon's Excavated Remains (2000), p.35.

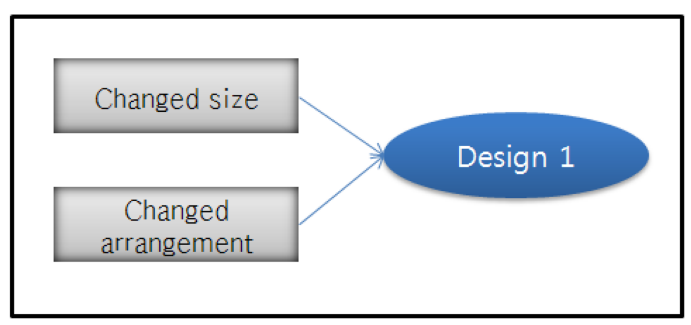

Fig. 2. Process of Design 1 with applying Jatmulim.

자형의 목둘레와 맞깃의 형태로 소매는 짧은 소매로 구성되었 다. 이러한 특징을 반영하여 소매는 9부로 제작하고 반수의의 목둘레 부분과 앞여밈 부분을 응용하였고, Fig. 4의 잣물림 응 용기법을 활용하여 Table 7과 같이 완성하였다. 앞 목선 중심 부분에는 잣물림의 형태를 변형한 사각형 모양을 겹쳐 U자형 앞 목둘레에 자연스럽게 연결함으로써 직사각형에서 부드러운 삼각형 모양으로 변화되다가 없어지도록 장식하였다. 이는 유 물에서 보이는 정형화된 깃을 잣물림을 이용하여 부드러운 느 낌의 깃 선으로 표현한 것이다. 양쪽 소매 끝에는 직사각형의 잣물림 변형을 장식함으로서 프릴(Frill)과 같은 장식효과를 주 어 화려한 느낌의 상의로 제작하였다. 
Table 6. Design 1

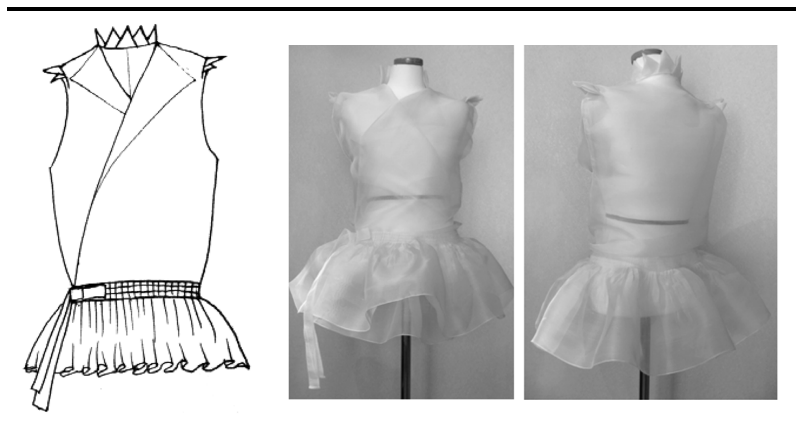

Color: White

Material: Silk 100\%

Stitch method: Double-stitching

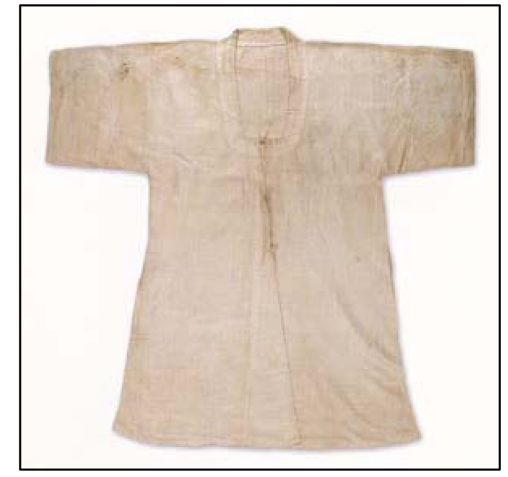

Fig. 3. Bansuui. Research Report of Jeonju Lee's Excavated Costumes (2001), p. 26.

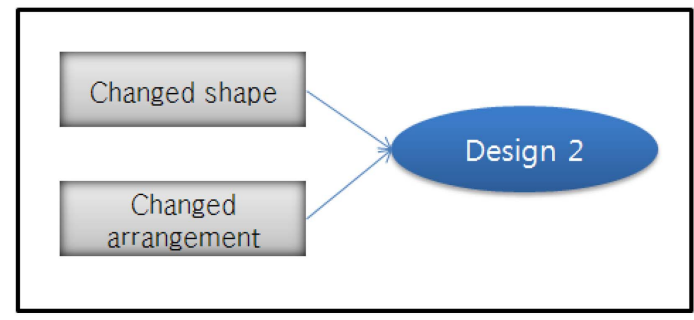

Fig. 4. Process of Design 2 with applying Jatmulim.

Design 3은 Fig. 5의 조선시대 남자 단령을 응용하여 제작하 였다. 단령은 남자의 관복으로 깃과 무의 모양이 시대에 따라 변화되었다(Lee, 2005). 단령의 둥근 깃 모양과 주름처럼 겹쳐 나타나는 옆선의 무의 모양을 응용하여 양쪽 옆 부분에 맞주름 이 있는 민소매의 한국적 여성 블라우스로 제작하였다. 이와 더 불어 Fig. 6의 잣물림의 형태와 배열의 변화를 목둘레에 활용 하여 Table 8과 같이 완성하였다. 완성된 모습은 소매 없는 단 령의 형상으로 목둘레 부분에 잣물림 기법을 응용함으로써 단 령의 형상을 부각하되 직사각형의 잣물림을 겹쳐 목선에 장식 하여 경쾌하고 귀여운 느낌으로 표현되었다.

Design 4는 Fig. 7의 조선시대 여성 저고리 구성법을 응용하
Table 7. Design 2

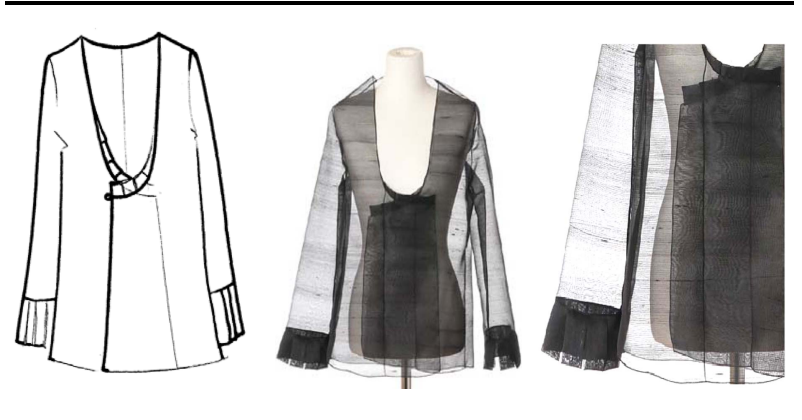

Color: Black

Material: Silk 100\%

Stitch method: Double-stitching

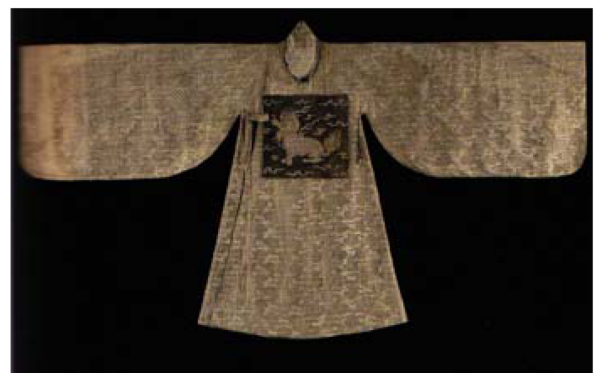

Fig. 5. Danryeong. The Story of a Military Officer's Costume in the 17th Century (2005), p. 55.

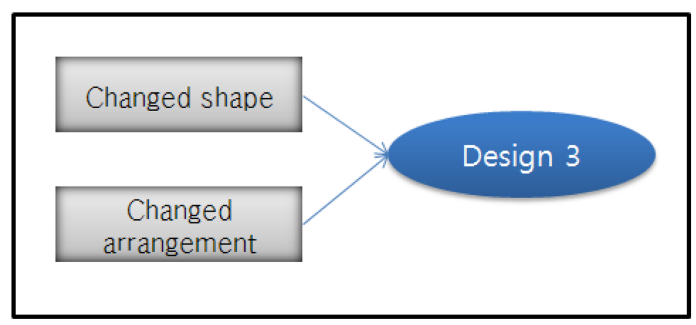

Fig. 6. Process of Design 3 with applying Jatmulim.

여 한국적 여성 상의로 제작하였다. 조선시대 여성의 저고리는 몸판, 깃, 섶, 소매로 평면으로 구성되는데 이러한 특징을 살리 고 이에 Fig. 8의 잣물림의 크기의 변화와 배열의 변화를 주어 Table 9와 같은 형태로 제작하였다. Table 9에서 보면 Design 4는 저고리와 같이 어깨를 직선으로 재단하여 저고리의 형태적 특징을 충분히 재현하고 잣물림의 크기 변화와 배열의 변화를 앞 중심 부분에 활용한 것이다. 완성된 여성상의는 앞섶 부분 에 크기가 확대된 잣물림을 3 줄로 겹쳐 장식함으로써 화려한 느낌이 부각되었다.

Design 5는 Fig. 9의 조선시대 답호의 형태를 응용하여 제작 한 한국적 여성 민소매 블라우스이다. 답호는 고려시대 유물에 서 보면 반소매에 이중 깃의 형태로 다른 포와 함께 덧입는 포였고(Yu \& Kim, 1998), 조선시대 출토유물에서 보면 반소매 
Table 8. Design 3

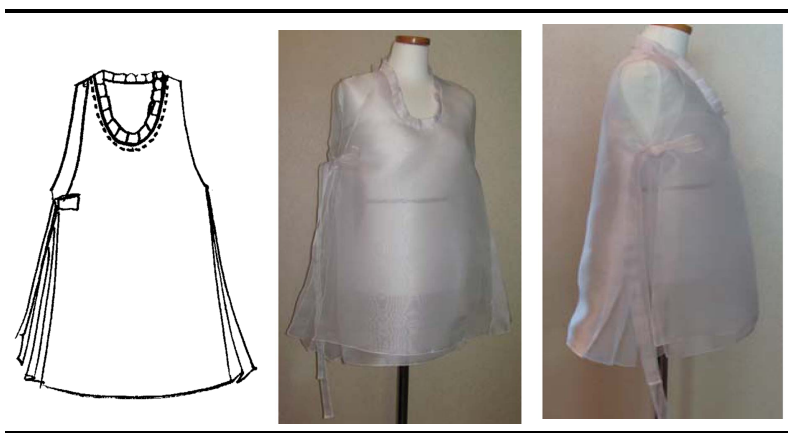

Color: White

Material: Silk 100\%

Stitch method: Double-stitching

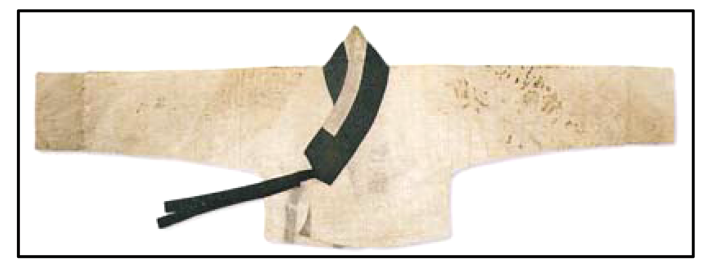

Fig 7. Jeogori. Research Report of Jeonju Lee's Excavated Costumes (2001), p. 43.

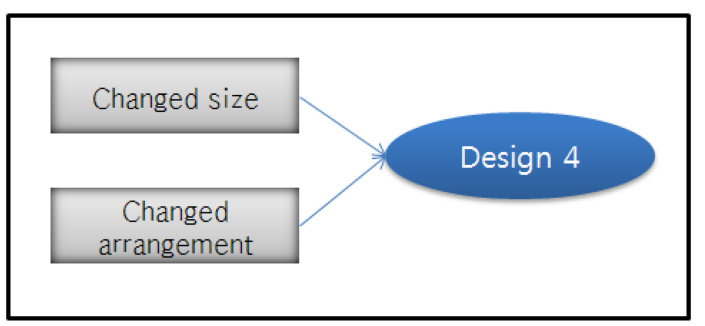

Fig 8. Process of Design 4 with applying Jatmulim.

Table 9. Design 4

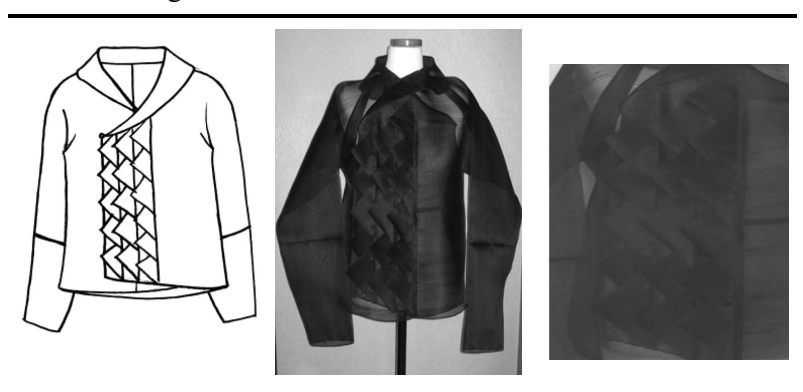

Color: Black

Material: Silk $100 \%$

Stitch method: Double-stitching

혹은 소매가 없는 형태의 의복으로 이 역시 다른 포 특히 철 릭과 함께 착용한 남자의 포이다(Song, 2009). Design 5는 이 러한 형태적 특징을 응용하여 소매가 없는 직령 형태로 디자인

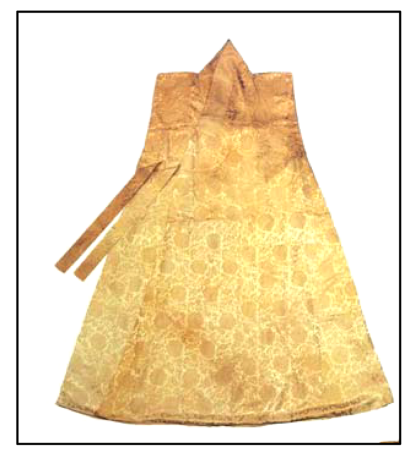

Fig. 9. Dapho. An Exhibition of Excavated Korean Costumes (2006), p.110.

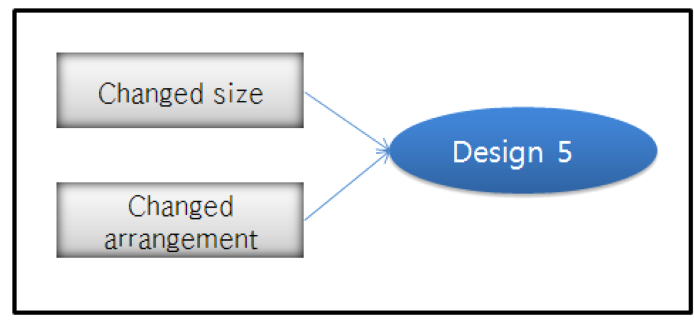

Fig. 10. Process of Design 5 with applying Jatmulim.

Table 10. Design 5

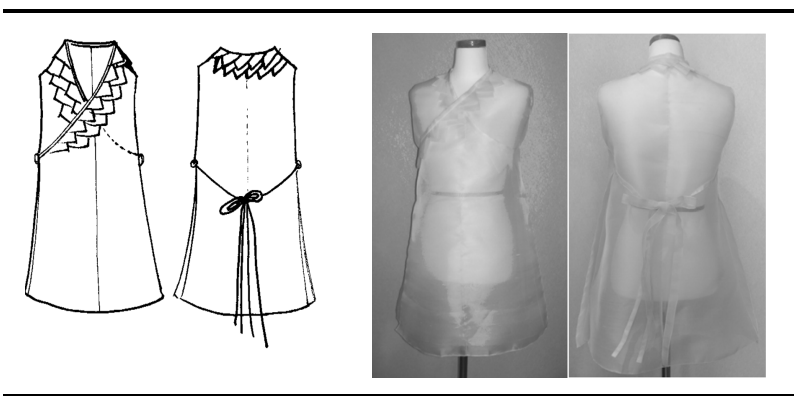

Color: White

Material: Silk 100\%

Stitch method: Double-stitching

하였고, 목선에는 Fig. 10 에서와 같이 잣물림의 크기의 변화와 배열의 변화를 응용하였다. 따라서 Table 10 의 완성된 작품은 직령의 단순한 형태에 깃 부분에 잣물림의 크기를 확대하고 깃 선을 따라 이중으로 배열하여 장식함으로써 여성스러운 느낌의 상의로 제작되었다.

\section{4. 결 론}

본 연구는 한국 전통 장식 기법의 하나인 잣물림 기법을 응 용하여 한국적인 상의를 개발하는 데에 목적을 두었다.

잣물림은 작은 천 조각을 삼각형으로 접어 의복 제작 시 선 사이에 물려 박아 장식했던 기법이다. 조선시대 유물에서 보면 
어린아이의 두루마기 깃과 무녀의 몽두의 깃, 어깨, 섶선에 장식 되었다. 현대 복식 디자인에서 보면 잣물림은 치마 내부의 선, 상의의 깃, 목선, 소매, 진동둘레에 장식되었고, 여아의 배씨 댕 기를 응용한 머리띠에 장식되거나 삼각형 모양으로 연결하여 가방의 앞부분에 장식되었으나 한국 전통의 잣물림 제작방법과 활용방법에서 크게 벗어나지 않았다. 이에 본 연구에서는 잣물 림의 방법과 형태를 응용하여 크기, 형태, 배열의 변형을 시도 하여 잣물림 응용 기법을 제시하였고, 이를 조선시대 출토유물 을 기반으로 한 한국적 상의 디자인에 장식하여 다섯 작품을 제시하였다.

Design 1은 조선시대 요선철릭을 응용한 한국적 여성상의의 하나로 민소매 블라우스이며, 목둘레와 소매 끝에 크기와 배열 에 변화를 준 잣물림 기법을 활용한 디자인이다.

Design 2는 조선시대 반수의 형태를 응용한 여성 재킷이며, 목둘레 부분과 소매 끝에 형태와 배열의 변화를 준 잣물림 기 법을 활용한 디자인이다. Design 3은 남자 단령의 깃 모양과 무의 모양을 응용한 민소매 블라우스이며, 칼라는 단령의 깃 모 양을 살리되 형태와 배열의 변화를 준 잣물림 기법을 활용한 디자인이다. Design 4는 저고리 구성법을 응용한 여성 재킷으 로, 겉섶 부분에 3 줄의 잣물림 장식을 하여 크기와 배열의 변 화를 준 잣물림 기법을 활용한 디자인이다. Design 5 는 답호의 구성법, 특히 여밈 형태를 응용하여 제작한 민소매 블라우스이 며, 깃 부분에 크기와 배열에 변화를 준 잣물림 기법을 활용한 디자인이다. 이상 다섯 작품에 장식된 잣물림 응용 기법은 각 각의 디자인에 여성스럽고 귀여운 이미지를 부각하는데 효과적 인 장식기법이었다.

본 연구는 한국 전통 장식 기법의 하나인 잣물림을 응용한 한국적 여성상의 디자인에만 국한하였지만 이를 기반으로 하여 다양한 한국적 의상 개발에 기반에 될 수 있는 자료가 되기를 기대한다.

\section{References}

Andong National University Museum. (2005). 17세기의 무관 옷 이야기 [The story of a military officer's costume in the 17th century] . Geongbuk: Andong National University Museum.

Choi, E. J. (1999). A study on the analysis of present situation of contemporary folk women's wear design. Journal of Korean Traditional Costume, 2(3), 39-52.

Cultural Heritage Administration. (1981). 조선시대 궁중복식 [Court dress in the Joseon period]. Seoul: Cultural Heritage Administration.

Gum, G. S. (1994). 조선복식미술 [Joseon costume art] . Gyeonggido: Youlhwadang.

Gyeonggi Provincial Museum. (2001). 전주이씨 묘 출토복식 조사 보고서 [Research report of Jeonju Lee's excavated costumes] . Gyeonggi-do: Gyeonggi Provincial Museum.

Hong, N. Y., Kim, N. J., Kim, J. A., \& Kim, J. Y. (2004). 한
복만들기 [Practice of handbook]. Gyeonggi-do: Kyomunsa.

Kim, G. I. (2003). A study on fashion designs using quilting techniques. Unpublished master's thesis, Hongik University, Seoul.

Kim, S. G., \& Lee, Y. A. (2010). A study on decoration techniques applied to the Korean traditional costume of contemporary style[Part I] - Focusing on Korean traditional costumes for women which were delivered between 2001 and 2005 -. Journal of the Korean Society for Clothing Industry, 12(5), 564-573.

Sookmyung Women's University Museum. (2000). Korean embroidery. Seoul: Sookmyung Women's University Museum.

Lee, C. C. (2011). A developing of clothing design through application of Korean traditional Chokagbo pattern. Unpublished master's thesis, University of Incheon, Incheon.

Lee, E. J. (2005). Development process of Sibok and Sangbok for officer in Joseon dynasty. Journal of Korean Society of Costume, 55(6), 38-50.

Lee, M. J., \& Choi, H. S. (2007). A study on contemporary fashion design with the application of Korean traditional embroidery I. Journal of Korean Society of Costume, 57(3), 176-190.

Lee, M. J., \& Choi, H. S. (2009). A study on comtemporary fashion design with the application of Korean traditional embroidery II. Journal of the Korean Society of Fashion Design, 9(1), 75-88.

Lee, Y. A. (2011). A study on the design model by analysis for the ornamental characteristics of the traditional handbook. Unpublished doctoral dissertation, Dongseo University, Busan.

Ok, M. S., \& Park, O. R. (2011). The types and characteristics of decorative techniques applied to the Korean traditional skirt of contemporary style - Focusing on 2001 to 2010-. Journal of Costume Culture, 19(4), 712-722.

'Sewing, ribbon crafts, tatting lace etc'. (September 19, 2010). Retrieved November 11, 2012, from http://blog.naver.com/fviam

Seok Juseon Memorial Museum of Dankook University. (2006). 衣 [Costume] . Seoul: Seok Juseon Memorial Museum of Dankook University.

Seoul Museum of History, Seok Juseon Memorial Museum of Dankook University. (2006). An Exhibition of Excavated Korean Costumes. Seoul: Seoul Museum of History.

Song, M. K. (2009). A study of Dap-ho(塔胡) in Joseon dynasty -Until the early 17th century-. Journal of Korean Society of Costume, 59(10), 51-67.

The National Folk Museum of Korea. (2000). 오백년의 침묵, 그 리고 환생- 원주 변씨 출토유물 기증전- [Silence of 500 years and reincarnation; donation exhibition of Wonju Byeon's excavated remains]. Seoul: The National Folk Museum of Korea.

The National Folk Museum. (2005). A comprehensive catalogue of Korean costume from the national folk museum of Korea collection. Seoul: The National Folk Museum of Korea.

The Korean Society of Costume. (1999). 1999 KOSCO Exhibition. Seoul: The Korean Society of Costume.

The Korean Society of Costume. (2000). 2000 KOSCO Exhibition. Seoul: The Korean Society of Costume.

The Korean Society of Costume. (2003). International Costume Conference. Seoul: The Korean Society of Costume.

Yu, G. S. (2012). A study on the design development of upper clothes 
in Saenghwal handbook. Journal of Korean Traditional Costume, 15(1), 69-83.

Yu, H. K., \& Kim, M. J. (1998). 한국복식문화사 [Cultural history of Korean costume]. Gyeonggi-do: Kyomunsa.
(Received 17 January 2013; 1st Revised 13 February 2013; 2nd Revised 17 February 2013; Accepted 15 March 2013)

Copyright (C) The Society of Fashion and Textile Industry. 2013. This is an open access article distributed under the terms and conditions of the Creative Commons Attribution Non-Commercial license (http://creativecommons.org/licenses/by-nc/3.0/), which permits unrestricted non-commercial use, distribution, and reproduction in any medium, provided the original work is properly cited. 